\title{
A Survey on Level of Client Satisfaction Among Clients Visiting out Patient Department at Felege Hiwot Referral Hospital, Amhara Reginal State, North West Ethiopia, 2015
}

\author{
Ayele Smachew Kasa* \\ Adult Health Nursing, Bahir Dar University, Ethiopia \\ *Corresponding author: Ayele SmachewKasa, Adult Health Nursing, School of Nursing, \\ College of Medicine and Health Sciences, Bahir Dar University, Bahir Dar, Ethiopia, Tel: \\ +251913959205; Email: ayele.semachew@yahoo.com
}

\section{Research Article \\ Volume 2 Issue 4}

Received Date: May 28, 2018

Published Date: June 14, 2018

DOI: $10.23880 /$ eoij-16000156

\section{Abstract}

Introduction: Service delivery refers to the systematic arrangement of activities in service giving in stitutions with the aim of fulfilling the needs and expectations of service users and other stake holders with optimum use of resources. Given the noticeable paucity of studies addressing out patient satisfaction among client in public Hospital setting, including Felege Hiwote Referal Hospital, the information obtained from this study will hopefully assist in determining the level of satisfaction among outpatient clients in Felege Hiwot referral hospital.

Method: A cross sectional study conducted from November 22 to December 26, 2015. All departments included in the study using systematic random sampling techniques. A total of 271 respondents were recruited. Structured questionnaire was used to collect the data. The report depicted descriptively using measures of central tendency, dispersion and using tables and graphs.

Result: Out of the total 271 respondents; 150(55.35\%) were females; Most of the Clients (32.47\%) were between1524yearsold. Sixty three (23.24\%) were illiterates. Most of the clients, $60(22.14 \%)$ were farmers while thirty $(11.07 \%)$ governmental employees, 30 (11.07\%).One hundred seventy seven (65.31\%) of clients comes from the rural areas of the region. Out of the total respondents, $60.88 \%$ werenew visitors. Nearly one third of the client's $94(34.68 \%)$ were on paying and received the services for free. This study has revealed that the satisfaction level with the outpatient services in the Fel egehiwot refer ral hospital was $62.01 \%$.

Conclusion: Many clients are found to be dissatisfied with service provision of the outpatient department soft he hospitals. These include in adequate information provision about the hospital services and the ir health problems, long 


\section{Ergonomics International Journal}

waiting time to get the hospital services. So the concerned body (Amhara Regional Health Bureau) need sound rested the extent of the problem and plan to look Fr different mechanisms to enable detailed satisfaction survey.

Keywords: Patient Satisfaction; Outpatient; Bahir Dar; Felege Hiwote Referal Hospital

\section{Background}

Service delivery refers to the systematic arrangement of activities in service giving in situations with the aim of full filling the needs and expectations of service users and other stake holders with optimum use of resources. Service is generally any activity under taken to meet social needs. Public service particularly refers to those activities of government institutions aimed at satisfying the needs and ensuring the well being of the society as well as enforcing laws, regulations and directives of the government [1,2]. Hospitals are an important part of any health system they provide-curative care, transfer knowledge, work as refer ral for patients. To achieve service excellence, hospitals require continuous efforts to improve quality of the service delivery system [1].

In the prior years when hospitals were symbols of human Italian efforts for community welfare, accountability for performance was of little concern [3]. Today however people are increasingly concerned dab out hospital's performance because hospital Susan increasing proportion of scarce community resources .There are increasing questions about quality and effectiveness. The reins increasingly evidence that appropriately addressing consumer's healthcare leads to improved healthcare outcomes. Expectations about quality of care are linked to perceptions of care, and when patient's perceptions are positive their clinical experience and outcomes are more likely to be positive [4]. Studies in Jimmy hospital, Gondar hospital and the hospital soft he Am hare region showed low client satisfaction because of long waiting time and unavailability of basic drugs $[5,6]$.

Through time, the significant increase in population growth has resulted in an extremely increased demand for health services, while the hospital capacity and facilities are not correspondingly changing. Out of the total 879,322 patients in the year 200 about (44.6\%) of them visited the zonal hospitals [7].

The Am hare regional Health Bureau is there for making different efforts that are still on process to full fill the hospitals with the right man power, medical equipment and other facilities to meet the needs of the clients [8,9]. However, although these efforts are undergoing to improve the service delivery, the needs of the people have no yet been adequately met.

Felege Hiwot referral hospitals are among the oldest hospitals in the region now serving for the people of the region that were originally established about more than 20yearsagoforamuchlesserpopulation [10]. According to the report of the Ministry of Health, 2004/2005, about 3.3 million outpatient users, 40,639 inpatients, about 600,000 diagnostic services users and 20,800 major and minor surgeries were served in the hospitals, showing that the yare accommodating beyond their capacity [11]. Given the noticeable paucity of studies addressing out patient satisfaction among client in public Hospital setting, including Felege Hiwot Referal Hospital, the information obtained from this study will hopefully assist in determining the level of out patient satisfaction and to describe main reasons of dissatisfaction among clients visited Felege Hiwot Referral Hospital.

\section{Method and Materials}

The study was conducted at Felege Hiwot Referral Hospital which is found in Amhara regional state, North West Ethiopia. Felege Hiwot Referral Hospital is located in Bahir Dar City which is the capital city of Amhara regional state and located $565 \mathrm{Km}$ away from the Addis Ababa the capital city of Ethiopia. The hospital is one of the biggest referral hospitals in the region that provides services to many inhabitants in region. Institution based cross-sectional study was done. All clients coming to the outpatient departments during the study period were included except those clients who were very seriously ill, who did not have somebody to accompany them because of the difficulty of interviewing, children who were alone. The sample size for each department was determined based on the number of clients served in each department. As a result, 271clients were involved in the study using systematic sampling technique. 


\section{Data Collection Instrument}

Structured questionnaire was designed to obtain information on socio demographic characteristics of respondent sand the irate faction level with the different components of the outpatient services which include the availability of drugs and supplies, information provision by the health workers, waiting time to get the services, and courtesy and respect of the health workers figure 1.

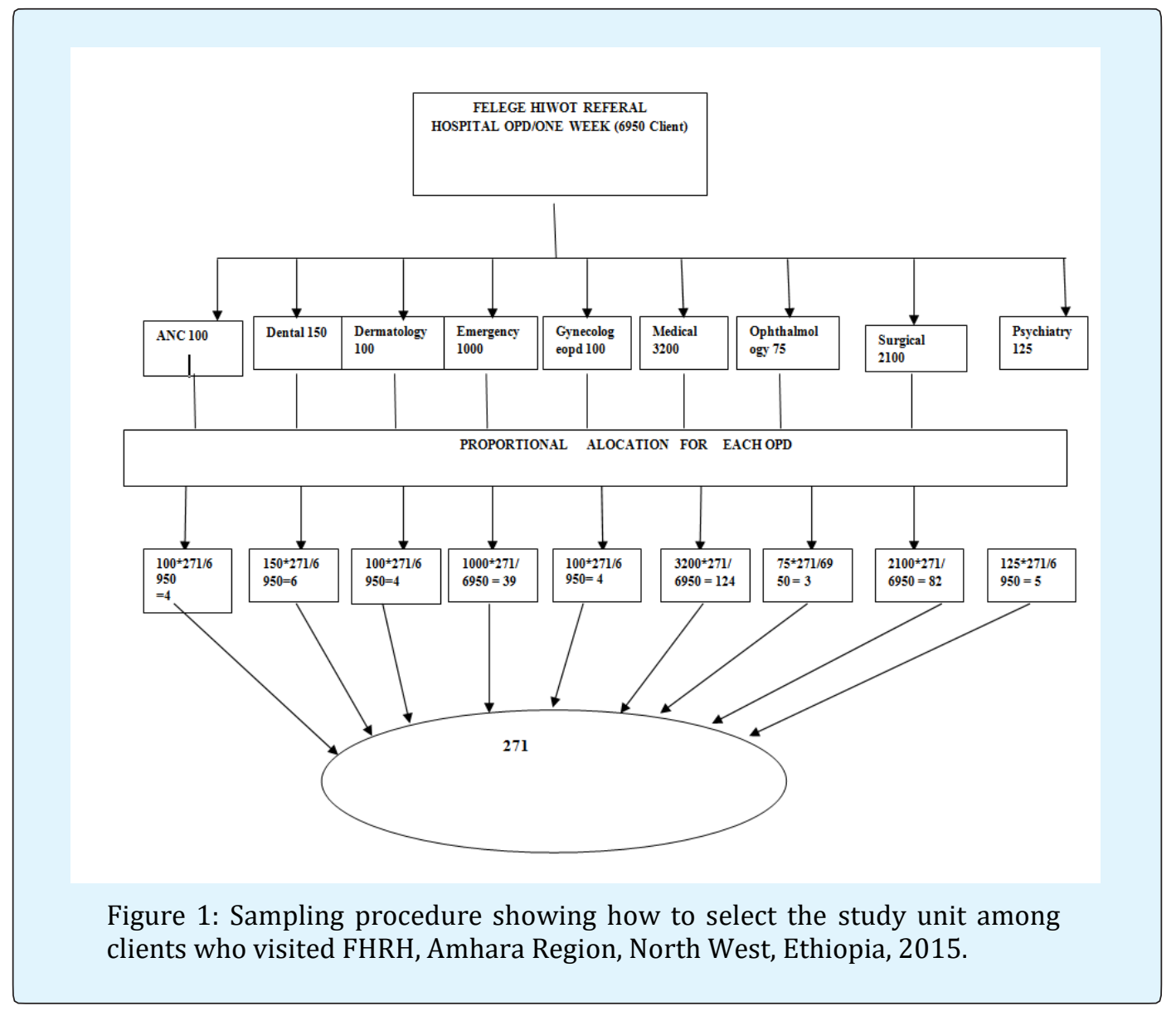

\section{Data Processing and Analysis Procedures}

The data will be edited, coded and entered into EpiData version 3.1 and exported to IBM SPSS Statistics Version 20 for analysis. Results of the data analysis will be presented in the form of descriptive statistics which included mean, standard deviation and percentages. Each item of the overall job satisfaction were measured by a four point liker scale having a total of 20 items and their sum score ranging from a minimum of 20 to maximum of 100. For cut of value purpose we used data driven classification system so that we classify client satisfaction level into low (value less than 35), moderate (values between 36 to76) and high (values above 76 of client satisfaction percentage score).

\section{Results}

The response rate of the current study is $100 \%$ and among all studies participants 150(55.35\%) were females, nearly one third of the clients $(32.47 \%)$ were between15-24years old. Sixty three (23.24\%) were illiterates. Regarding the impartial status, 138 (50.92\%) was unmarried. Twenty two percent were farmers while $11.07 \%$ were governmental employees. Out of the total respondents, $60.88 \%$ were new visitors. Nearly one third of the client's $94(34.68 \%)$ were non paying and received the services for free (Table1). 


\section{Ergonomics International Journal}

\begin{tabular}{|c|c|c|}
\hline Socio Demographic Characteristics & $\mathbf{n}$ & $\%$ \\
\hline \multicolumn{3}{|c|}{ Sex } \\
\hline Male & 121 & 44.6 \\
\hline Female & 150 & 55.4 \\
\hline \multicolumn{3}{|c|}{ Age (in years) } \\
\hline $15-24$ & 88 & 32.5 \\
\hline $25-34$ & 72 & 26.6 \\
\hline $35-44$ & 30 & 11.1 \\
\hline $45-55$ & 39 & 14.4 \\
\hline$>=56$ & 42 & 15.5 \\
\hline \multicolumn{3}{|c|}{ Educational status } \\
\hline Illiterate & 63 & 23.2 \\
\hline $1-6$ grade & 45 & 16.6 \\
\hline $7-12$ grate & 93 & 34.3 \\
\hline Diploma and above & 70 & 25.8 \\
\hline \multicolumn{3}{|c|}{ Address } \\
\hline Urban & 94 & 34.7 \\
\hline Rural & 177 & 65.3 \\
\hline \multicolumn{3}{|c|}{ Payment status } \\
\hline Paying & 177 & 65.3 \\
\hline Free & 94 & 34.7 \\
\hline \multicolumn{3}{|c|}{ Service getting need } \\
\hline Client & 267 & 98.5 \\
\hline F.P. and vaccination client & 4 & 1.5 \\
\hline \multicolumn{3}{|c|}{ Frequency of visit } \\
\hline New & 165 & 60.8 \\
\hline Repeat & 106 & 39.1 \\
\hline \multicolumn{3}{|c|}{ Would you recommend the services of this hospital to someone else? } \\
\hline Yes & 168 & 62 \\
\hline No & 103 & 38 \\
\hline
\end{tabular}

Table 1: Socio Demographic Characteristics of the clients in the outpatient departments of Felege Hiwot Referral Hospital, Amhara Regional state, North West Ethiopia, 2015. (n=271).

This study has revealed that the satisfaction level with the outpatient services in the Felegehiwot referral hospital was $62 \%$. Courtesy and respect of health care provider was the aspect where satisfaction was ratedhighest183 (67.52\%). Dissatisfaction was reported by nearly half of their respondents with the lack of drugs and supplies in the hospitals 'pharmacies 105 (42.67\%). Access and clean lines of the hospitals artiness were the other aspects where satisfaction level was less compared to the other aspects.

Nearly One third of their pendants (34.7\%) responded they were not satisfied with the information provision about the hospital services and the flow. $58.67 \%$ of the respondents reported laboratory, x-ray/ultrasound examinations were ordered to them while $95.1 \%$ of the total clients got a prescription paper for drugs and supplies (Table 2). 


\section{Ergonomics International Journal}

\begin{tabular}{|c|c|c|c|c|c|c|c|c|c|c|c|}
\hline \multirow{2}{*}{ Characteristics } & \multicolumn{2}{|c|}{ Very satisfied } & \multicolumn{2}{c|}{ Satisfied } & \multicolumn{2}{c|}{ neutral } & \multicolumn{2}{c|}{ dissatisfied } & \multicolumn{3}{c|}{ Very dissatisfied } \\
\cline { 2 - 14 } & $\mathrm{n}$ & $\%$ & $\mathrm{n}$ & $\%$ & $\mathrm{n}$ & $\%$ & $\mathrm{n}$ & $\%$ & \multicolumn{2}{c|}{$\mathrm{n}$} & $\%$ \\
\hline $\begin{array}{c}\text { Information provision } \\
\text { By health workers }\end{array}$ & 45 & 16.6 & 132 & 48.7 & 15 & 5.5 & 48 & 17.7 & 31 & 11.4 \\
\hline Time spent to see a physician & 36 & 13.3 & 138 & 50.9 & 27 & 10.0 & 61 & 22.5 & 9 & 3.3 \\
\hline Courtesy and respect & 60 & 22.14 & 123 & 45.4 & 3 & 1.1 & 54 & 19.9 & 31 & 11.4 \\
\hline Privacy & 69 & 25.5 & 105 & 38.7 & 22 & 8.1 & 57 & 21.03 & 18 & 6.6 \\
\hline Access to latrines & 18 & 6.64 & 57 & 21.03 & 21 & 7.7 & 130 & 48.0 & 45 & 16.6 \\
\hline $\begin{array}{c}\text { Cleanliness of latrines/toilet } \\
\text { Overall waiting time }\end{array}$ & 12 & 4.42 & 42 & 15.5 & 25 & 9.2 & 138 & 51.0 & 54 & 20.0 \\
\hline To get the services & 13 & 4.7 & 139 & 51.2 & 19 & 6.90 & 98 & 36.1 & 3 & 1.1 \\
\hline Availability of drugs and supplies & 57 & 23.2 & 114 & 46.3 & 15 & 6.1 & 51 & 20.1 & 9 & 3.7 \\
\hline $\begin{array}{c}\text { How satisfied are you by the waiting } \\
\text { Time to get the health service and get } \\
\text { back? }\end{array}$ & 36 & 13.3 & 138 & 50.9 & 27 & 10.0 & 61 & 22.5 & 9 & 3.3 \\
\hline $\begin{array}{c}\text { How satisfied are you by the way the } \\
\text { doctor s examined you? }\end{array}$ & 60 & 22.14 & 123 & 45.4 & 3 & 1.1 & 54 & 19.9 & 31 & 11.4 \\
\hline $\begin{array}{c}\text { Were you satisfied with the measures } \\
\text { Taken to assure confidentiality about } \\
\text { your health problem? }\end{array}$ & 69 & 25.5 & 105 & 38.7 & 22 & 8.1 & 57 & 21.03 & 18 & 6.6 \\
\hline $\begin{array}{c}\text { How do you evaluate the overall } \\
\text { Cleanliness and comfort of the waiting } \\
\text { area, examination room and the } \\
\text { compound? }\end{array}$ & 12 & 4.42 & 42 & 15.5 & 25 & 9.2 & 138 & 51.0 & 54 & 20.0 \\
\hline
\end{tabular}

Table 2: Level of satisfaction of clients with the different components in the outpatient departments of Felege Hiwot Referral Hospital Amhara Regional state, North West Ethiopia, 2015. (n=271).

\section{Discussion}

This study has revealed that the satisfaction level with the outpatient services in Felege Hiwot Referral Hospital was $62 \%$.This is in line with a study conducted in Jimma hospital and Mozambiqu which showed $57.1 \%$ and $55 \%[12,13]$, On the other hand this finding was higher than a study conducted by other researchers22\% and 37\%inGondar,Mekelle regional referral hospital respectively $[6,10]$. Another study was conducted in Hawassa University teaching hospital southern Ethiopia revealed that $80.1 \%$ was satisfied [14]. When we have compared with this, it shows low satisfaction level. The suggested reasons for this difference could be, due to the better attention by the concerned governmental higher officials and the efforts made to make changes in the service delivery process of the hospital by involving their staffs that insisted them to assess the existing problems in the hospitals. Another study conducted in Singapore hospitals has revealed that $40 \%$ of the total number of patients reported service quality was below their expectations [3].
In this study nearly $34.8 \%$ of the clients are paying and $4.9 \%$ of those clients with prescription paper for drugs did not get the ordered drugs from the hospital pharmacies. This is better compared to a study conducted in Micelle referral hospital showed $86.6 \%$ of the clients received the prescription paper for drugs out of which $82.2 \%$ of them were not able to get the prescribed drugs from the hospital pharmacy [15].

Forty six point seven percent $(46.7 \%)$ of the clients were dissatisfied with the provision of information about the hospital services and their health problems. This is quite a high dissatisfaction rate when compared to the study conducted in Family planning service delivery points in Bahr DarCity with a $25.2 \%$ dissatisfaction rate [16]. The reason for this discrepancy could be due to the difference in the service provided, number and type of health care providers. Another study conducted in Mekelle regional referral hospital so reported that incompleteness of information to the clients out the hospital services and their conditions was identified as one of the sources for client dissatisfaction [12]. 


\section{Ergonomics International Journal}

Highest satisfaction rate $(93.8 \%)$ was found with the courtesy of the health care providers. This is nearly a similar finding when compared with a study conducted in private wing of Felege Hiwote Referal Hospital which showed nearly84.4\% satisfaction rate on good provider greeting and respect in the governmental family planning service delivery points including the hospital [13].

In a study conducted in Mekelle referral hospital long waiting time to get the services was found to bone of the sources for the clients' dissatisfaction [12]. In line with this study; waiting hours for getting hospital services were too long almost in all of the hospital services in the Amhara region hospitals [6].

\section{Limitation}

The study did not focus on the health care providers. Lack of resource.

The findings may not be generalized to clients in other health care facilities like health centers and private health institutions, as the different environment and circumstances may impact on client's satisfaction.

\section{Conclusion}

The level of clients' dissatisfaction is high in the outpatient departments of the Felegehiwot referral hospital. Many clients are found to be dissatisfied with service provision of the outpatient departments of the hospitals. These include: inadequate in formation provision about the hospital services and their health problems and long waiting time to get the hospital services.

\section{Declarations}

\section{- Acknowledgements}

For data collectors and the study participants

\section{- Funding}

No fund was obtained

\section{- Availability of data and materials}

Not applicable

\section{Authors' Contributions}

AS wrote the proposal, participated in the data collection, analyzed the data, and drafted the paper including the manuscript.

\section{- Competing interests}

The authors declare that they have no competing interests.

\section{- Consent for publication}

Written consent was obtained that the interview will be included in publications.

\section{- Ethics approval and consent to participate}

Ethical clearance was obtained from Bahir Dar University, College of Medical Sciences and health sciences, research and community service coordinator. A formal letter of cooperation was written to the hospitals. Participants were informed about the purpose, benefit, risk, the confidentiality of the information, and the voluntary nature of participation. Data were collected only after informed written consent was obtained.

\section{References}

1. (2001) Service delivery policy in the civil service.

2. Surjit SW (2001) Customer satisfaction and health care delivery system: Commentary with Australian Bias. The Internet Journal of Nuclear Medicine 1(1).

3. Lim PC, Tang NK (2000) A study of patients' expectations and satisfaction in Singapore hospitals. Int J Health Care Qual Assur Inc Leadersh Health Serv 13(67): 290-299.

4. WHO (2000) World Health Organization report, Geneva.

5. Olijera L, Gebresilasses S (2001) Satisfaction with outpatient health services at Jimma hospital, South West Ethiopia. Ethiop J Health Dev 15(3): 179-184.

6. Dagnew M, Zakus D (1997) Community perception on OPD performance of a teaching hospital in Gondar town. Ethiop Med J 35(3): 153-160. 


\section{Ergonomics International Journal}

7. Tigray Health Bureau (2004) Planning and Programming Department, Annual Health Profile (1996ECT).

8. World Health Organization report (2003) Measuring hospital performance to improve the quality of care in Europe: A Need for Clarifying the Concepts and Defining the Main Dimensions. Geneva.

9. (2002) Health Sector Strategy. Ministry of Health.

10. Felge Hiwot (2014) Referral Hospiatl Office report.

11. (2003) Health and Health related indicators. Ministry of Health.

12. Newman RD, Gloyd S, Nyangezi JM, Machobo F, Muiser J (1998) Satisfaction with outpatient health care services in Manic province, Mozambique. Health Policy and Planning 13(2): 174-180.
13. Yeshambel AA, Amsalu FD, Measho GG (2014) Patient satisfaction and associated factors among private wing patients at Bahir Dar FelegeHiwot Hospital North West Ethiopia. Science Journal of Public Health 2(5): 417-423.

14. Anteneh Asefa, Andargachew Kassa, Muluken Dessaleg (2014) Patient satisfaction with outpatient health services in Hawassa University Teaching Hospital, Southern Ethiopia Journal of Public Health and Epidemiology 6(2): 101-110.

15. Annual Report (2002/2003) Federal Ministry of Health AA.

16. Wale Tseganeh (2014) Assessment of the knowledge and skill of family planning service delivery points, in Bahrdartown. Master's thesis, AddisAbaba, 2005 west Ethiopia. 